\title{
Digital Accounting and the Human Factor: Theory and Practice
}

\author{
Shawnie Kruskopf, Charlotta Lobbas, Hanna Meinander, Kira Söderling, \\ Minna Martikainen and Othmar M. Lehner*
}

Hanken School of Economics, Helsinki

\section{ARTICLE INFO}

Article history:

Received 04 April 2019

Revised 10 June 2019 and 08

January 2020

Accepted 11 May 2020

Published 27 May 2020

\section{Keywords:}

Digitalisation

Accounting

Auditing

Industry 4.0

Skills

\section{ABSTRACT}

This paper gives an overview of the current and future technologies impacting the accounting and auditing fields. The aim is to present the technological disruptions shaping these fields and also look at how they might influence future jobs and required skills. Starting with a historical background check on how Industry 4.0 emerged, we surveyed four main areas of the topic:

1. Current developments supported with real-life cases

2. A literature review of ongoing research

3. Possible future job descriptions and

4. Required skills and how to acquire them.

\section{Introduction}

In this paper, we looked at how current and future technologies will impact the fields of Accounting and Auditing and how they shaped the future in terms of new job descriptions and required skills in these fields. These fields are moving with full force into the digital age, where many predict that in five to ten years, humans will become obsolete in many areas of Accounting and Auditing.

However, though many tasks will be automated, humans will still be able to create value for clients and for the way the business world is developing through continuous learning of new skills. Here we will discuss how humans can grow alongside advancing technologies to keep up with the demand that will be present in a few short years. To do this, we will first introduce the Fourth Industrial Revolution and its advancements. Next, we will review how this 'Revolution' is changing the world of accounting and auditing, presenting which technologies and advances are relevant to the fields and are creating the largest impacts. In addition, we will review ongoing research from (e.g. Zhang, Dai \& Vasarhelyi, 2018, Pan \& Seow, 2016, and others) and how it is affecting the fields, jobs, and the skills required to adapt. Once we set up this potential future, we will go through additional demands that will be placed on employees of the fields. Next, a detailed list of the most valuable skills going into the future will be analyzed. We will then discuss an overview of the critiques that are forming due to the rapid changes that are occurring in the fields, including employment opportunities. And lastly, we will predict how the future will evolve in our view and from the view of the ongoing research.

\footnotetext{
* Corresponding author. 
While there are many predictions of how the future would be when many tasks have become automated, many reports do not focus on what will be required of the employees-going forward to add value to clients. This report gives an in-depth analysis of new job descriptions and which skills will be potentially needed to survive in a digital future of accounting and thus allowing for further research on which of these skills are the most useful going forward.

\section{Theoretical framework}

The revolution in which we are now has many names, such as the 4th Industrial Revolution, Industry 4.0 (which we will use in our paper), The Digital Revolution, and the Artificial Intelligence Revolution (Hoffman, 2017). The McKinsey Global Institute estimates that "It's happening 10 times faster and at 300 times the scale than the Industrial Revolution in the early 19th century" (Hoffman, 2017). In order to understand the potential future in accounting and auditing, we first must understand the revolution we are in now. In this section, we will discuss what Industry 4.0 is, how it will change the future and how it will specifically change accounting and audit.

The fourth industrial revolution is a continuation of the third revolution or its advanced level in which we started to use computers and automation to improve upon it with autonomous and smart systems, driven by data and machine learning. In the current revolution; when Industry 4.0 evolves further, computers will be interconnected and will communicate to make decisions without humans. This is a level of the revolution where computers are going to interact among themselves just like humans, in its operations and services. The combination of the; Internet of Things, the Internet of Systems, and Cyber-physical Systems, makes Industry 4.0 possible. The power in the Industry 4.0 lies in the network of smart machines that are interconnected and can create, analyze and share information (Marr, 2018). In other words, Industry 4.0 is about the ways in which smart-connected technologies will be embedded in companies, assets, and people, and is marked by the development of analytics, robotics, cognitive technologies, artificial intelligence, quantum computing, the Internet of things, amongst others. One of the most important parts of these new technologies is that they will change the way data and related information are used and how this will allow companies to gain know-how and become more efficient (Cotteleer \& Sniderman, 2017). Overall, Industry 4.0 is changing every aspect of the business world and has become an inevitable topic of discussion. Next, we move on to the specifics that are changing the fields of accounting and auditing.

The Accounting and Auditing professions are evolving, and everyone is talking about the digital revolution. The revolution is growing fast, and there are still many aspects that are unclear about the future. These changes will lead to the disappearance of many jobs, but at the same time, it will allow for many new opportunities not only for the newly graduated but also for those who are eager to develop new skills. Information technology is nowadays part of every business, and companies that can't keep up with the new technologies will slowly fade away. Just like every other field in Business, Accounting and Auditing will benefit immensely when using digitalization to organize, process, and evaluate financial data, which will improve productivity and save both cost and time.

These changes will affect, essentially, every business as accounting is a crucial and core part of the success of any company, and we have seen how failures in this area have wiped out large and bustling companies such as Enron and WorldCom (Edupristine, 2018). For those legally required to participate in audits, these improving technologies will also affect them and help them to uncover fraud, inconsistencies, and other faults that could topple a business. A further subset of these companies that will be affected is the accounting firms, from the top four to the smallest and everything company in-between.

As the digital revolution is shaping the field of accounting and auditing, it means that this topic is relevant for both current accounting and auditing professionals as well as for Students and Professors at universities as they are the ones that have the knowledge required to develop these sophisticated accounting information systems. We already know that many of the current accounting processes are being done by machines such as Expense Management, Accounts Receivable and Payable Processing, Artificial Intelligence-powered Invoice Management, and Supplier Onboarding.

Thus, we can predict enormous changes in jobs in the future, but the role of bookkeepers and auditors will remain important. One of the most important discussions currently open is how there are a lot of tasks that machines can 
perform much better and faster than humans, such as structured problem solving and routine tasks but then again, they don't have the skills of improvising and using imagination (Hoffman, 2017). We will further discuss how humans can adapt to stay competitive and add value in the fields mentioned in subsequent sections.

To sum up, these current advancements are making it necessary for businesses, accounting and auditing professionals, upcoming graduates, and universities to adapt to technology and figure out the best way to interact with it going forward.

\section{Current developments}

Businesses have gone through three different waves of transformation up to the present day. From the first wave of standardized processes of automobiles on assembly lines to the second wave of automated processes including Computers, Information Technology, Databases, and Software. Built on these two, the third wave includes Adaptive Processes. This wave initiates new ways of doing business. Based on real-time data, these processes are more adaptive and flexible and gives the possibility to reimagine innovation and more individualized products and services (Daugherty \& Wilson, 2018). According to Charles Hoffman (2017), there are three technological innovations that are primarily driving the changes of the current accounting practices, methods, and procedures and which can noticeably modernize and improve accounting and auditing. These are XBLR-based structured digital financial reporting, knowledge-based systems, and other applications of artificial intelligence and blockchain-based distributed ledgers.

XBLR-based structured digital financial reporting stands for eXtensible Business Language Reporting, which is a global standard for exchanging business information that is freely available for everyone. In the past, financial reports were readable only by humans, but in the future, they will be both human-machine-readable (Hoffman, 2017). The second innovative driver in the field are knowledge-based systems and other applications of artificial intelligence (Hoffman, 2017). Robotics and Artificial Intelligence are at the center of technological disruption. Robotic Process Automation (RPA), is about automating structured and rule-based tasks. RPA is not intelligent in the sense that it cannot adjust to changes or make complicated decisions (Zhang, 2018). In the area of RPA, accounting firms and RPA companies are collaborating. All big four accounting firms, Accenture, Capgemini, and others are working with Robotic Process Automation companies such as UiPath and Blue Prism (Tadros, 2016). AI research has reached a new level of development and understanding of machine intelligence. The current approach has focused on letting the system learn rules by itself from observations collected from real-life data, instead of teaching the system a wide range of rules (ICAEW, 2018). Going forward, AI will reduce costs and time for accountants and auditors as it works in the background, enhancing already existing cloud computing and increasing productivity (G2 Crowd, 2018).

The third technological innovation driving the fields and affecting future jobs is the Blockchain-based Distributed Ledgers. Blockchain is a shared database with a series of data that is time-stamped and immutable, so no one can tamper with the data. The blockchain is a decentralized system - it has no master. The records are tied together into blocks and then they are added to the chain one by one. No transaction costs arise when using Blockchain, because no intermediaries are needed. It is an easy way to pass information from one person to another in a completely automated way. The blockchain is hosted by millions of computers at the same time, so the data is open for anyone on Internet (Blockgeeks, 2019).

Although it is at an early stage, Blockchain is changing the accounting and auditing world. Companies are already testing the new technology. New opportunities and challenges for professionals in accounting and auditing will arise due to the blockchain. Blockchain is best known as the technology behind cryptocurrencies, such as Bitcoin, but it has many other potential uses and benefits in addition to that (Half, 2018). Examples of such potential uses are; Property Records, Banking, Supply-chain-Auditing, Anti-money Laundering (AML), Know Your Customer (KYC), Stock Trading, Smart Contracts, and Crowd Funding (Blockgeeks, 2019). 
The main advantages of Blockchain in accounting and auditing is that:

- It enables more efficient asset and data transfers

- Privacy and security will increase

- Time-consuming tasks can be removed and

- Financial records will become more comprehensive and precise.

Blockchain technology may also open up new job tasks for auditors, such as cyber auditing (Half, 2018).

As it can be seen around us and as we have talked about in this paper, the trend is that data and operational processes are more and more transferred into digital form. Unfortunately, new technology and processes bring new forms of corruption and fraud. Cybersecurity is therefore an inevitable part of strategy planning both now and in the future. Companies have to invest and manage these new risks of cybercrimes (Gupta, 2015). Accounting firms are doing their best to protect their businesses. A rapidly evolving feature of AI is anomaly detection. Accounting firms use this application of machine learning to prevent cybercrimes and to identify outliers in the data such as, in cases of identification of false invoices for their clients. For example, Ernst \& Young's (EY) Anomaly Detection Program has an accuracy of $97 \%$ and is a valuable tool in everyday work for accountants and auditors (Zhou, 2017), and in order to protect both the assets, reputation, and staff of the accounting firms, but also their customers (Gupta, 2015). According to Daugherty \& Wilson (2018), it is a misconception to think that machines will gradually replace humans in labor markets. They think the man-versus-machine view is old-fashioned and short-sighted. Instead, we should start to think about it as a collaboration between humans and machines. They emphasize that even though technology will probably replace certain jobs and certain functions, the main power of the technology is in complementing human capabilities. Many leading firms have begun exploiting the potentials of AI in their businesses and have started to realize that organic teams including humans partnering with machines are the future. Humans and machines, each have their own strengths. The areas where each party is most capable and in which areas they complement each other are represented in table 1. Many of these human-only activities and skills will be explained later in the article. The important part of the table is to see and acknowledge the "missing middle", as Daugherty \& Wilson (2018) explain it, where humans and machines complete each other. This middle is often forgotten, when we compare human and machine activities as excluding each other.

Table 1. Human-Machine teamwork (modified Daugherty \& Wilson, 2018, p. 5 and Marr, 2018b)

\begin{tabular}{|c|c|c|c|c|c|c|c|c|c|c|c|c|c|}
\hline ָூָ & 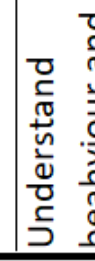 & 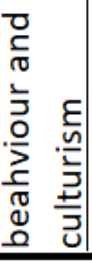 & مِ & $\stackrel{\frac{5}{\pi}}{\stackrel{5}{上}}$ & $\begin{array}{l}\frac{.}{\pi} \\
\frac{0}{x} \\
\end{array}$ & $\frac{.5}{\pi}$ & $\frac{\text { 党 }}{\frac{2}{\varepsilon}}$ & 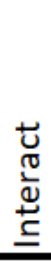 & 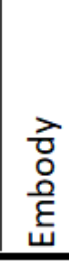 & 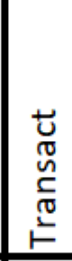 & $\begin{array}{l}\stackrel{0}{*} \\
\frac{0}{ \pm} \\
\pm\end{array}$ & $\begin{array}{l}\frac{.}{0} \\
\frac{1}{2} \\
\stackrel{2}{2}\end{array}$ & $\frac{+}{2}$ \\
\hline \multirow{2}{*}{\multicolumn{4}{|c|}{$\begin{array}{l}\text { Human-only } \\
\text { activity }\end{array}$}} & \multicolumn{3}{|c|}{$\begin{array}{l}\text { Humans } \\
\text { complete } \\
\text { machines }\end{array}$} & \multicolumn{3}{|c|}{$\begin{array}{c}\text { Machines } \\
\text { complete } \\
\text { humans }\end{array}$} & \multirow{2}{*}{\multicolumn{4}{|c|}{$\begin{array}{l}\text { Machine-only } \\
\text { activity }\end{array}$}} \\
\hline & & & & \multicolumn{6}{|c|}{$\begin{array}{l}\text { Human-machine hybrid } \\
\text { activities }\end{array}$} & & & & \\
\hline
\end{tabular}

Apart from these three innovative drivers in the field, there are expanding industries that will now and also in the future affect accounting and auditing. Two of these new industries are FinTech and RegTech. FinTech stands for Financial Technology, and it describes the businesses that use modern technology and software to provide financial services. Fintech companies are competing with the banking sector. They provide different digital solutions in daily banking, such as Robo-advisors and different apps. This enables, for example, faster and easier transactions without intermediaries (FinTech Weekly, 2019). RegTech Regulation Technology addresses regulatory challenges by 
simplifying the increasing legal requirements within the financial industry (W. Arner et al. 2017). RegTech Companies use, for example, AI and machine learning to come up with new regulatory solutions (ComplyAdvantage, 2018). These new technological approaches save accountants' and auditors' time in mundane tasks in areas of compliance and managing money (G2 Crowd, 2018). This has and will result in changes in job tasks and skills needed by employees.

\section{Actual Business Cases}

Many of the top players in accounting and auditing have been exploiting and investing in different innovative areas to stay relevant in the field. As it was presented in the previous part, the main buzzwords disrupting the nature of accounting and auditing work now and in the near future are Robotic Process Automation, Artificial Intelligence, Blockchain, Human-Machine Teamworking, and new security issues. While many of these technologies are still in their infancy, they are already creating a lot of value for the investors. In addition, many of these technologies are allowing companies, accountants, and auditors to take on more global clients without as many limitations as before. In this section, we looked at some current examples of development affecting the work of the future accountants and auditors.

\section{Case: PwC Digital Accelerator Program}

In order to train their employees and keep them on top of the development, PwC (PricewaterhouseCoopers) launched a 2-year Digital Accelerator Program for 1,000 employees to boost their digital skills in 2018. The aim of the Digital Accelerator program is to train the employees in-house in three areas; data analytics, automation, and AI, including machine learning. The program includes courses from data cleansing, blockchain, cybersecurity to drones and 3D printing. Instead of doing their usual work, the participants in the program got "digital-heavy" projects, client work to solve, and attend weekly classes. The Digital talent leader and the head of the Digital Accelerator program, Sarah McEnaneuy says that the aim of the program is that the employees get more technological skills so that PwC can remain competitive in the market. The program is also an attempt to reduce costs for clients. The costs can be reduced, thanks to the new technology that enables job tasks to be done faster. PwC did not reveal how much they are spending on the project but did tell that it was one of the largest investment areas in 2018 (Liffreing, 2018).

\section{Case: Deloitte US Blockchain Lab}

Deloitte has dedicated a whole division to blockchain research and development. The US Blockchain lab is located in New York and is one of the many blockchain labs that Deloitte has around the world. Deloitte's blockchain community consists of over 800 professionals in 20 countries. The aim of the lab is to support clients in utilizing the capabilities and opportunities that blockchain technology can offer. A lab is a place for education, ideas, development, strategy, and prototyping. The team in the US consists of more than 20 committed designers and developers in Blockchain. The US Blockchain team works together with a specialist from other countries and with more than 20 technology companies. The lab has already developed over 30 prototypes that are Blockchain-related, covering a variety area of applications, such as trade finance, cross-border payments, digital identity, fraud detection, reward programs and a lot has also been done in the investment management and insurance sectors. An example of a blockchain solution that can be of great benefit in the accounting and auditing fields, is the fraud detection solution that is blockchain and machine learning-based. This solution facilitates fraud detection in real-time. If anomalies are detected in the transactions, they are captured and get a risk score created based on the matching transaction IDs in the blockchain (Deloitte, 2019).

\section{Case: The EY Blockchain Analyzer}

EY has started to use blockchain technology in its audit process. It was in April 2018 that EY announced the pilot of the EY Blockchain Analyzer, which is a technology that is created to help auditors to collect a company's transaction 
data from various blockchain ledgers. When the data is collected, auditors can examine the data, analyze the transactions and identify outliers. The technology makes it possible to do a thorough analysis of the business transactions in cryptocurrency. The technology is specifically created to support auditors when they audit companies that use cryptocurrencies. Cryptocurrencies such as Bitcoin, Ether, LiteCoin, Bitcoin Cash, and a few other cryptoassets are being tested with this technology. When the Blockchain analyzer has been developed, they have used the experience acquired when working with clients around the world, with technologies such as wallet providers, investment funds, exchange platforms among others. The development of this new technology is an answer to the customer's changing needs and to improve the audit process as a whole. As the EY Global Assurance Innovation Leader, Jeanne Boillet, says: "As digital technology continues to advance, we are focused on developing innovative approaches to the audit process and providing confidence and trust to the capital markets. As companies are also focusing on how they embed technologies like blockchain into their financial processes, we are innovating the audit to meet their evolving needs and those of investors" (Thomas, 2018).

\section{Case: PwC and $A B B Y Y$}

PwC has started to automate its financial documentation processing in cooperation with ABBYY. Auditing requires dealing with a large number of documents and verifying that the content correlates with the information in the customer's accounting system. In the past, the employees at PwC have manually keyed the data into the system. This required of course a lot of time when they had to analyze every document for important information. PwC did, in order to increase the efficiency and automate the data transfer, implement the ABBYY FlexiCapture intelligent solution for automated data collection and document processing. ABBYY uses artificial intelligence to provide content intelligence solutions and services. This technology makes the data transfer from invoices, contracts, and other structured and unstructured documents much faster. When, for example, an auditor uploads documents to the ABBYY server, the ABBYY FlexiCapture can automatically identify document types and improve images. It can also identify which documents should be dealt with and can extract the required data and further transfer the data into a master spreadsheet. The auditors benefit from this because, they can spend a lot more time with their customers instead of doing paperwork (ABBYY, 2019).

\section{Case: Natural Language Processing in the leading accounting firms}

Natural Language Processing (NLP), is a form of AI application that plays a big part in the ongoing developments in accounting and auditing. In its simplest form, NLP is the technology behind tools such as spellcheck, autocorrect, and in the Google search function that tries to figure out what you are going to say (Mills, 2019). This efficient form of AI combines both computers and linguistics (Mills, 2019), and it is guided by deep-learning that learns from examples and automatically obtains useful information for its user. From this extracted data, an Accountant or Auditor can acquire practical insights to use in one's work (Onyshkevych, 2018). Here we will look at how EY, Deloitte, and PwC embody AI at the moment. Each of them has a somewhat different approach to development. EY addresses it from a business value perspective, by doing small things and aiming to get in this way an immediate ROI. EY uses NLP in reviewing lease accounting standards in cases when the IRS issues new regulations.

Previously, they had to go through tens of thousands of contracts, but now NLP does this faster and humans only have to validate the results from the automatically extracted information. PwC employs AI as short AI sprints, where they develop quickly in four weeks, a functioning model for a client. If approved, they refine it to provide better accuracy for the client. These sprints include teams of two or three people, and $\mathrm{PwC}$ holds approximately 80 sprints a year. Deloitte also takes its own approach in deploying AI in the company's operations. They have an internal innovation team that focuses on every angle of new technology and devotes $80 \%$ of their time to AI. Their NLP system can, for example, look through hundreds of thousands of legal documents in different client cases, and this way save months of time from humans (Zhou, 2017).

Next, we will look into ongoing research in these topics to provide a link between the practical and theoretical. 


\section{Ongoing research}

From ongoing research, we have found many papers referring to the need for accountants and auditors to improve their skills. For example, according to Greenman's paper "Exploring the Impact of Artificial Intelligence on the Accounting Profession", research shows that employees need to upgrade their skills because of the changes occurring in the fields. Accountants are being forced to adapt or risk losing their jobs. The good news is that while there will be job disruptions, there will be new jobs being continuously created. According to the US Bureau of Labor and Statistics: "The accounting profession is projected to grow at a rate of 11 percent over the next 10 years, an increase of over 142,000 new accounting and auditing jobs" (Greenman, 2017). Greenman further speculates that there are most likely many factors contributing to this growth in the US, but a large amount will be due to the technological advancements that need accountants to have the right knowledge to make the advances work successfully. This paper shows that, yes, the accounting and auditing roles are changing, but from recent technological advancements, they have not made all jobs obsolete. On the contrary, individuals with the right skills have used these technologies such as tax filing software to increase the number of clients they can take on. This further proves that with the right skills, the future will be bright.

Looking further into research done in the fields, we can already see that there is a huge lack of IT knowledge in the accounting and auditing professions and that the need for these skills is becoming more important than ever before. There is already a need for professionals who have IT knowledge in auditing, data analytics, and people who can handle these sophisticated IT services and programs. In Pan \& Seow's (2016) article, they critically reviewed the competencies and skills that future accounting graduates need to prepare for. It is shown that the use of cloud computing, eXtensible business reporting language, and business analytics have already set some changes in how companies do their financial reporting. The emerging use of information technology in almost every part of the accounting field has made the demand for accounting graduates to have advanced IT skills even more critical. The conclusion from the research is that it is crucial that accounting students should have proper training in IT tools such as automatic identification systems, XBRL, analytical programming, and data mining because this is what the future in the field will be all about; analyzing and developing these IT accounting systems. This means that the education and courses in the universities need to be more focused on IT-related topics (Pan \& Seow, 2016). Further evidence from research on the topic is that accounting education is lacking the depth and breadth of the current evolving accounting practices. The author is reflecting the situation by the fact that the role of technology and information systems are not embraced enough in the current accounting textbooks (Wells, 2018).

In another research recently done by Zhang, Dai, and Vasarhelyi (2018), the focus is on the impacts of disruptive technologies and how they will change the accounting and auditing profession as well as the education. As for today, there is still a lack of Information Technology in education, which means that the students aren't prepared for the accounting workplace of the future. The most important question is about how the profession is going to adapt to the technological changes and how it will change the traditional procedures. One thing that is certain is that the automation will result in a substantial reduction of staff, especially from the traditional tasks. Automated processes mean that the accountants and auditors will need to focus on the technical maintenance of the systems and more analytical work, while repetitive and mundane tasks will disappear.

Mentioned, here again, the technologies that are reshaping the accounting business models are robotic process automation, artificial intelligence, advanced analytics programs, and blockchain and these require more sophisticated education that will focus on these high-level skills. These changes will mean that the educators at the business schools will have to use new teaching models that could include, for example, cybersecurity and audit data analytics classes. All in all, the future of the accounting and auditing profession will require a philosophy of lifelong learning and ongoing adaption to the changing environment (Zhang et al. 2018).

Lastly, we focused on audit processes, the research again goes through the disruptive technologies and how they will affect accounting and auditing. In this paper, the focus is on audits and how AI is changing what parts humans play in the audits. To begin, there are already many advancements that have taken over certain tasks, this is due to the sheer amount of data, structured and unstructured that companies process. In Kokina and Davenport's; "The 
emergence of artificial intelligence: How automation is changing auditing" research, they explained how, due to the requirements of audits, AI technology is a perfect fit. Yet the advancements will reduce many entry-level audit jobs, which is where many accountants start their careers.

This will take away a learning opportunity for many new graduates as they won't have a job waiting for them. The next step already being foreseen by the big four accounting firms is "Making increasing use of audit platforms and predictive analytics, but not the higher levels of intelligence and cognitive capability". They have used technology to reduce repetitive tasks, but still cannot take the emotional intelligence side and fit it into new technologies. Thus, while current entry-level jobs may be replaced, we are moving towards a combination of humanmachine work, rather than full automation. With Kokina and Davenport predicting that; "Since AI technologies replace specific tasks rather than entire jobs, loss of employment in the short term is likely to be relatively slow and to be marginal rather than dramatic." This research opens further questions about, "Bias in AI and whether humans using AI applications can engage in appropriate judgment and decision-making." and how transparent it is to use AI if humans are not interpreting the results correctly (Kokina \& Davenport, 2017).

\section{Future job descriptions}

There is no doubt that the accounting and auditing professions will change sooner than later because of the digital revolution that we are presently in. When time-consuming tasks are done by machines, professionals can focus on adding more value to their customers which will reduce both cost and time spent on the given tasks. The automation of regular accounting processes will lead to accountants and auditors being able to focus on more specific tasks because many of the earlier tasks will be done by computers. Traditional accounting procedures such as in-house invoicing and travel invoicing will be replaced by computers. Auditing processes will be automated and there will be advanced tools to detect risk and fraud. Future auditors will be able to focus on analyzing the outputs instead of using several hours on collecting information from financial statements (Forbes, 2018).

The future jobs of accountants and auditors will be all about using sophisticated information systems and artificial intelligence to analyze, report, and develop wanted outputs. Sophisticated information systems will take care of handling data security, connecting different parts of the financials which will become part of the big data. The revolution is changing the tasks related to Management Accounting and Financial Accounting.

In the future, the Management Accounting tasks will be more precise and detailed because of the computer's ability to collect and gather the information that is needed for managers to make the right decisions. Accountants in the field can then focus more specifically on preparing and analyzing the data for those who are interested. The problem that Accountants might face is the overwhelming amount of information that will be available. This means that the accountants' jobs will be about recognizing the relevant and important information to be able to make decisions. These tasks require strong communication skills to be able to share the most important results in a clear way. Although computers are taking over, one important fact is that the quality of the data will remain important.

To be able to produce quality data, there is a need for someone who can transfer the information and serve as a service agent when working on transferring knowledge to the systems. This task can't be done without an expert in the field. As time passes and robots are part of the daily tasks of accounting and auditing professions, there is going to be a need for someone at the user level support as well as someone who is capable of solving the technical problems related to the systems. We don't know the specific job descriptions of the future accountant and auditor, but from existing information, we have gathered a list of potential future job description titles presented in the following table. 
Table 2. Examples of future job titles, source: authors based on literature review

$\begin{array}{lll}\text { Blockchain Accountant } & \text { Analytics Guru } & \text { Historical Accounting Analyst } \\ \text { Healthcare Accountant } & \text { Cloud Accounting specialist } & \text { Systems Integrator } \\ \text { Cybercrime Accountant } & \text { Fintech City planner accountant } & \text { Strategic Accounting Analyst } \\ \text { Fintech Accountant } & \text { Data Security Accountant } & \end{array}$

Now that we have seen what kind of jobs might be offered in the future, we need to figure out how we can adapt and overcome to be the kind of employee companies will be looking for. To start, the base knowledge of accounting and auditing will always be necessary thus, the skills mentioned here are ones that are needed in addition to what accountants/auditors should already somehow know. To conquer this topic, we have broken the skills down into more technical skills as "Hard Skills" and then into so-called "Soft Skills", which are not always taught in conventional education.

Table 3. Potential required skills now and in the future, source: authors based on the literature review

\begin{tabular}{|c|c|c|c|}
\hline \multicolumn{2}{|c|}{ Technical skills } & \multicolumn{2}{c|}{ Social skills } \\
\hline $\begin{array}{c}\text { Understanding the } \\
\text { capabilities of software }\end{array}$ & Basics of coding & Strong communication & $\begin{array}{c}\text { Emotional intelligence, } \\
\text { ethical }\end{array}$ \\
\hline Analysis skills & Fintech software knowledge & Conflict solving & $\begin{array}{c}\text { Adaptability, tolerant of } \\
\text { uncertainty }\end{array}$ \\
\hline $\begin{array}{c}\text { Data visualization } \\
\text { Knowledge of International } \\
\text { Standard }\end{array}$ & $\begin{array}{c}\text { Data security, forensic tools } \\
\text { management }\end{array}$ & Leadership skills & Sales knowledge \\
\hline $\begin{array}{c}\text { Knowledge of industry } \\
\text { specific regulations }\end{array}$ & $\begin{array}{c}\text { ERP (Enterprise resource } \\
\text { planning) experience }\end{array}$ & Strategic decision making & Innovative/creative \\
\hline
\end{tabular}

The "technical or hard" skills include analysis, understanding of software and its capabilities, and data security knowledge amongst others, mentioned in Table 3. These are more about learning how to interact with programs, AI, robotics, and generally with the digitalization process that will take over mundane tasks. As mentioned before, many tasks will become hybrid human-robot tasks, there will be a need for people who know how to interact with the machines (Daugherty \& Wilson, 2018).

As for the "social or soft" skills, these are generally harder to learn in a class, they take patience, understanding, and the ability to adapt. While technical skills have always been deemed important, these soft skills are becoming equally valuable because they will allow individuals to bridge the gap between machines and people. As the accountancy and audit professions move towards a more strategic and insights-based field, these soft skills will become even more necessary. The individuals who master these skills will be immensely better off when dealing with clients who will no longer look at their Accountant/Auditor as a source for just financial statements, but as someone who knows their business inside-out and can provide valuable knowledge. Thus, gone will be the days of the quiet, back-office accountant, so expect to have employers increasingly ask for adaptability, innovativeness, sales skills, effective communication, and customer-oriented support capabilities (Marr, 2018b).

While the thought of needing so many skills may seem overwhelming, it is not necessary nor expected that every employee will be competent in all these areas. As mentioned earlier, jobs will most likely take a turn towards more 
specialized roles thus requiring employees to develop skills in certain areas. The advice here would be to explore many areas, select the topmost interesting ones but only specialize in a selected few that show a promising future.

How to acquire the necessary skills?

Now that we know what kind of skills will be required, we can move on to where to acquire these skills. Due to the technological advances of the last 25 or so years, the way to gain knowledge has expanded increasingly. No longer do you need to attend a physical class when almost everything is online. Presented here are some of the best ways to expand your skillset for the future. Starting with online courses, these are offered on platforms such as edX.com, Coursera.com, in these websites you can take courses from the Arts \& Humanities, social sciences, business, to languages. The variety on these websites is increasing rapidly. In addition to just taking one or two classes, they offer fully online master's degrees from accredited universities. They also offer certifications in different professional areas such as data science, cybersecurity, deep learning, and many other beneficial skills. Many of the courses are free, but to have them recognized you need to pay a fee, while a master's may set you back about $10-25 \mathrm{k} €$ depending on the program (edX.com). This may seem like a lot to spend, but compared to a campus master's degree, the cost is relatively cheaper.

In addition to online courses, you can still attend class at a university, for example through Open University, where you only pay per credit. This offers face-to-face interaction with professors and other students. Here is where you can learn the material taught in class, but also how to work better in teams.

Both options mentioned are especially great for people who are already working to be able to continue learning. In addition to seeking outside learning, it may be possible to ask your own organization to provide further in-house training. This shows employee initiative to progress in their career but is also a way to help the company grow in the inevitable digital future.

Moving on to possible quick learning solutions, there are other options such as YouTube, where knowledgeable individuals can share their insight in different areas and the same with Podcasts. Beware of these though as there could be some misleading or incorrect information. There is also plenty of LinkedIn training that is specifically geared towards accounting and auditing. Lastly, while not the most convenient way to learn, take a chance and volunteer for leadership or teamwork experiences, to build up technical skills and also some of the interpersonal skills mentioned previously.

Table 4. Examples of ways to expand one's skillset, source: authors

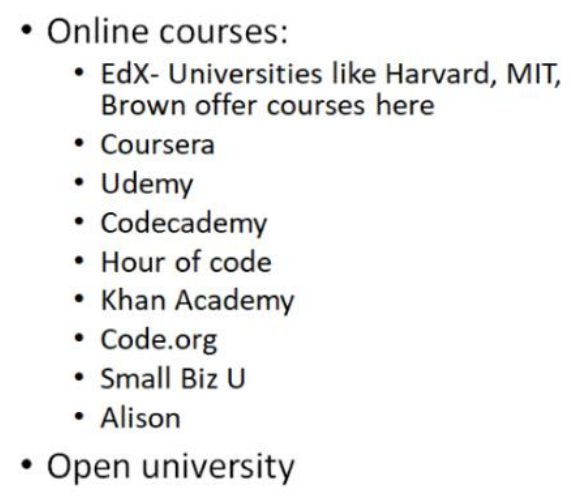

- Training courses offered by own company

- YouTube- channels:

- "Executive Finance"

- "CPA Strength"

- Linkedln trainings

- Podcasts

- Volunteering for leadership or teamwork positions

There are endless ways to acquire the skills needed for the future and many of these are even free. Accounting and auditing will be changing and moving forward, so now is not the time to rest on what you know, but to start the habit of continuous learning which will be necessary to keep up in these fields. 


\section{Critical voices from society}

Although, the overall opinion from the top players is positive regarding Industry 4.0, there are still some critical and worrying attitudes towards the future of accounting and auditing and how it will affect future jobs and professionals in the fields. Changes in the workforce and labor markets are often viewed with doubt and fear. Some of these concerns towards the digital revolution are, however, the same as they were already in the First Industrial Revolution (Najjar, 2019). The most common fears and threats circle around questions of jobs, security, and needed skills of employees. Also, comes the fact that our current society may not be ready for all the changes that Industry 4.0 brings, and big changes to our society's structure cannot be avoided (Marr, 2016).

Another thing that many in the field are wondering about is how to teach those entering the accounting and auditing field? The Entry-Level Accountants will most likely be the ones most affected in the labor market, due to the automatization. The reason for that is that they are usually performing the basic accounting and auditing tasks that will be automated. Consequently, some fear that entry-level workers will not be able to get appropriate hands-on experience early in their careers (Kokina \& Davenport, 2017).

In addition, many older workers feel that they are being left behind in the transition to the digital age. They fear not being able to retrain enough to stay competitive in the field. Employees older than 50 years of age are on average, facing challenges associated with new technology and automation, and therefore fear that younger people will take over their jobs. In addition to this, it has been discovered that employers do not give the older workforce the same opportunities to receive training to enhance their skills in the digital era. The biggest uncertainty arises from not having any insight into the future role in their company (Recruitment Revolution, 2018). This does not only include the older workers but also the younger ones who will need to retrain their skills due to the increasing pace of change and automatization in society. The future will require the average person to adapt to new changes "that would have previously taken several generations" (Dickinson, 2018).

Schwab outlined in his book; "The fourth industrial revolution", the potential risks with the revolution we are in now. He pointed out that organizations can be unwilling or not able to adjust to the changes and that governments can fail in the application and regulation of the new technology (Marr, 2016). The implementation of new technology is complex, time-consuming, and, under some circumstances, expensive. This can be a problem for smaller firms; they may not have the capability to implement new technology to the same extent as, for example, the Big 4 accounting firms, and therefore may not be able to keep up with the changes (Caramela, 2018). Further, Schwab assumes that there will pop up new security concerns and that inequalities can increase if things are not handled properly. When automation increases, a lot of jobs will be lost across many industries, as workers are replaced by computers and machines. According to an estimate, as much as $47 \%$ of the U.S jobs will be in the risk zone (Marr, 2016). We should, however, keep in mind that, although some jobs disappear, new ones will emerge.

CFOs are under a lot of pressure from all the challenges in the digital age. The concern in the CFO's responsibilities is on the ever-broadening areas in their tasks. Their role has never been more difficult than it is now. They are under the demand to obtain and analyze real-time data all the time, have the right skill set to understand the new technology, support the correct training of their staff and also hire new employees with the appropriate skills (Ernst \& Young 2016).

Risk management will continue to be an issue, and constant topic as technology may advance faster than companies, and employees are able to keep up with it. Related to CFO's responsibilities in the ongoing technological disruption, CFOs reported in a survey of more than 700 CFOs in 2018 that cybersecurity breaches are among the most critical things that keep them up at night (Korn Ferry, 2018).

\section{Conclusions and Future Outlook}

These are exciting times. The financial world, as we know it, is being turned upside down. With continuous digitalization and innovation, it is hard to predict with certainty how the affected fields will look in 10 to 15 years from now. Yet through our research that we have presented, potential tools and skills will most likely be needed and 
be useful to have a successful and long career in either accounting or auditing. To do this, we reviewed the sector's current and upcoming advancements, the potential job descriptions that will shape who gets employed, and finally, how to potentially acquire the knowledge needed.

What do we expect from the future then? After all our research, we know that robotics and AI are at the center of the change, and therefore humans will need to adapt to the changes coming with this. As we mentioned previously, many fear that these changes will make humans obsolete, but the further we research, the less we find this to be true. We have entered an age of human-machine cooperation that will continue as far as we can currently predict. At this point, many organizations still do not know how Industry 4.0 impacts their businesses or are struggling with other things, such as how to find the right talent and knowledge to know how to adapt to the changes. Thus, it is necessary and inevitable that many organizations are implementing changes and preparing for a different future with new technology that will improve their businesses. Industry 4.0 is still developing, and we cannot probably see the complete picture until many years in the future. However, the companies that adopt new technologies realized the potential future. The same companies are also dealing with how to educate their current workforce so that they can handle the new job tasks that Industry 4.0 brings and recruit new employees with the right skills (Marr, 2018).

Specifically, in the future of the accounting and auditing professions, it has become abundantly clear that the role of accountants and auditors is changing. Time-consuming and repetitive work will be automated, and the future accountant and auditor will perform higher-value work while transforming into more advisor roles in finance and business, with more specific expertise (Forbes, 2018). This will allow these individuals to focus their brainpower on more fulfilling tasks, but those that did not adapt will not make it through the next rounds of advancement. Thus, we know that now is the time for those interested in staying in these fields to push themselves to keep learning and improving because there will be no other choice.

From ongoing research, we have seen a shortage of required skills, especially with new graduates whose knowledge is coming directly from universities (Pan \& Seow, 2016). While it might be a slow change due to bureaucracy, we see education systems, specifically universities, changing their programs to be more technologyoriented and forward-looking. In addition to universities, we know companies will need to invest in technology and in their employees' skillsets. We predict that while investments may be expensive, it will be more expensive to lose out on business and risk bankruptcy.

Overall, we expect a promising and innovative future, where human-machine cooperation will be key and the individuals with the right skillsets will be set to prosper in this future. Yet, as we know the future is unpredictable, so further research will be needed to guide businesses, accounting and auditing professionals, and the society at large in the right direction.

\section{References}

Abbyy, 2019. PwC efficiently automates financial document processing with ABBYY. Available: https://www.abbyy.com/enus/case-studies/pwc-efficiently-automates-financial-document-processing-with-abbyy/\#sthash.g79OQuHI.dpbs. Retrieved: 2.3.2019

Blockgeeks, 2019. What is blockchain technology? A step-by-step guide for beginners. Available: https://blockgeeks.com/guides/what-is-blockchain-technology/. Retrieved: 1.3.2019

Caramela, S. (2018). AT\&T's Anne Chow on why small businesses shy away from early tech adoption. Business News Daily. Available: https://www.businessnewsdaily.com/10742-anne-chow-att-tech-adoption.html Retrieved: 7.3.2019

ComplyAdvantage, 2018. What is Regtech and why is it becoming the next big thing? Published: 9.7.2018. Available: https://complyadvantage.com/blog/what-is-regtech/ Retrieved: 1.3.2019

Cotteleer, Mark \& Sniderman, Brenna, 2017. Forces of change: Industry 4.0. Published: 18.12.2017. Available: https://www2.deloitte.com/insights/us/en/focus/industry-4-0/overview.html Retrieved: 21.2.2019.

Daugherty, P. R., \& Wilson, H. J. (2018). Human+ machine: reimagining work in the age of AI. Harvard Business Press.

Deloitte (2019). Blockchain Lab. Available: https://www2.deloitte.com/content/dam/Deloitte/ie/Documents/Technology/IE_C_BlockchainLab_210mmx210mm_0117.p df Retrieved: 1.3.2019

Dickinson, K. (2018). Top 6 fears about future technology. Big Think. Available: https://bigthink.com/technologyinnovation/fear-future-technology Retrieved: 27.2.2019 
Ernst \& Young (2016). The evolving role of the CFO in the digital age. Available: https://www.ey.com/Publication/vwLUAssets/EY-the-evolving-role-of-the-CFO-in-the-digital-age/\$FILE/EY-theevolving-role-of-the-CFO-in-the-digital-age.pdf Retrieved: 6.3.2019

Forbes (2018). The Digital Transformation of Accounting and Finance - Artificial Intelligence, Robots and Chatbots. Available: https:/www.forbes.com/sites/bernardmarr/2018/06/01/the-digital-transformation-of-accounting-and-finance-artificialintelligence-robots-and-chatbots/\#463edabe4ad8 Retrieved: 27.2.2019

G2 Crowd (2018). Can artificial intelligence be the future of accounting? G2 Crowd. Available: https://blog.g2crowd.com/blog/accounting/artificial-intelligence-future-accounting/ Retrieved: 28.2.2019

Gepp, A., Linnenluecke, M. K., O’Neill, T. J., \& Smith, T. (2018). Big data techniques in auditing research and practice: Current trends and future opportunities. Journal of Accounting Literature, 40, 102-115.

Greenman, C. (2017). Exploring the Impact of Artificial Intelligence on the Accounting Profession. Journal of Research in Business, Economics and Management, 8(3), 1451-1454.

Gupta, M. (2015). 5 Reasons Why Every Company Needs a Cybersecurity Strategy. Strategic Thinking. Available: http://www.strategicthinking.eu/5-reasons-why-every-company-needs-a-cybersecurity-strategy/ Retrieved: 2.3.2019

Half, Robert, 2018. What impact will blockchain have on the future of accounting and auditing? Published: 30.7.2018. Available: https://www.roberthalf.co.uk/advice/industry-insights/what-impact-will-blockchain-have-future-accounting-and-audit Retrieved: 1.3.2019

Hoffman, C. (2017). Accounting and auditing in the digital age.

ICAEW (2018). Artificial intelligence and the future of accountancy. Available: https://www.icaew.com//media/corporate/files/technical/information-technology/technology/artificial-intelligence-report.ashx Retrieved: 27.2 .2019

Kokina, Julia., Davenport, Thomas H. (2017). The Emergence of Artificial Intelligence: How Automation is Changing Auditing. Journal of Emerging Technologies in Accounting. 2017. 14(1), 115-122.

Korn Ferry. (2018). CFO Pulse Survey. Available: http://engage.kornferry.com/2018-cfo-pulse-survey Retrieved: 2.3 .2019

Liffreing, I. (2018). PwC launches 2-year digital skills course to train 1,000 employees on everything from drones to blockchain. Digiday UK. Available: https://digiday.com/marketing/pwc-launches-two-year-digital-skills-course-train-1000-employeeseverything-drones-blockchain/ Retrieved: 2.3.2019

Marr, B. (2016). Why everyone must get ready for the 4th Industrial revolution. Forbes. Published: 5.4.2016. Available: https://www.forbes.com/sites/bernardmarr/2016/04/05/why-everyone-must-get-ready-for-4th-industrialrevolution/\#ff5a3db3f90b Retrieved: 25.2.2019

Marr, B. (2018a). What is industry 4.0? Here's A super easy explanation for anyone. Published: 2.9.2018. Available: https://www.forbes.com/sites/bernardmarr/2018/09/02/what-is-industry-4-0-heres-a-super-easy-explanation-foranyone/\#1cdcbe8c9788 Retrieved: 15.2.2019

Marr, B. (2018b). 7 Job Skills of The Future (That AIs And Robots Can't Do Better Than Humans). Forbes. Available: https://www.forbes.com/sites/bernardmarr/2018/08/06/7-job-skills-of-the-future-that-ais-and-robots-cant-do-better-thanhumans/\#2ff950b56c2e Retrieved: 1.3.2019

Mills, T. (2019). Four Natural Language Processing Techniques to Increase Your Understanding. Forbes. Available: https://www.forbes.com/sites/forbestechcouncil/2019/01/31/four-natural-language-processing-techniques-to-increase-yourunderstanding/\#bc133b658940 Retrieved: 1.3.2019

Najjar, D. (2019). Is artificial intelligence (AI) the future of accounting? The Balance. Available: https://www.thebalancesmb.com/is-artificial-intelligence-the-future-of-accounting-4083182 Retrieved: 25.2.2019

Onyshkevych, B. (2018). Deep Exploration and Filtering of Text (DEFT). DARPA. Defense Advanced Research Projects Agency. Available: https://www.darpa.mil/program/deep-exploration-and-filtering-of-text Retrieved: 1.3.2019

Pan, G., Seow, P. 2016. Preparing accounting graduates for digital revolution: A critical review of information technology competencies and skills development. Journal of Education for business, 91, 166-175.

Recruitment Revolution (2018). How older workers can prosper in the digital era. Available: https://www.recruitmentrevolution.com/blog/2018/03/how-older-workers-can-prosper-in-the-digital-era Retrieved: 27.2.2019

Swart, G. (2013). Work as you go. The European Magazine. Available: https://www.theeuropean-magazine.com/gary-swart-2/7117-the-future-of-work-in-the-digital-age--4. Retrieved: 27.2.2019

Tadros, Edmund. (2016) Deloitte, KPMG, Accenture fight to help clients use robotic process automation. Financial review. Published: 27.9.2016. Available: https://www.afr.com/business/accounting/deloitte-kpmg-accenture-fight-to-help-clientsuse-robotic-process-automation-20160926-groqgo. Retrieved: 3.3.2019

Thomas, J. (2018). EY announces blockchain audit technology. Available: https://www.ey.com/en_gl/news/2018/04/eyannounces-blockchain-audit-technology Retrieved: 27.2.2019

W. Arner, Douglas, Zetzsche, Dirk A, Buckley, Ross P. and Barberis, Janos Nathan, 2017. Regulating a Revolution: From Regulatory Sandboxes to Smart Regulation. 23 Fordham Journal of Corporate and Financial Law 31-103 (2017).

Wells, P. K. (2018). How well do our introductory accounting text books reflect current accounting practice?. Journal of Accounting Education, 42, 40-48. 
Young, Joseph. 2018. How big four auditors delve into blockchain: PwC, Deloitte, EY and KPMG approaches compared. Available: https://cointelegraph.com/news/how-big-four-auditors-delve-into-blockchain-pwc-deloitte-ey-and-kpmgapproaches-compared Retrieved: 11.2.2019

Zhou, A. (2017). EY, Deloitte and PwC Embrace Artificial Intelligence for Tax and Accounting. Available: https://www.forbes.com/sites/adelynzhou/2017/11/14/ey-deloitte-and-pwc-embrace-artificial-intelligence-for-tax-andaccounting/\#60e6f5534982 Retrieved: 1.3.2019

Zhang, Chanyuan Abigail. (2018). Beyond robotics: How AI can help improve the audit process. Published: 1.8.2018. Available: https://blog.aicpa.org/2018/08/beyond-robotics-how-ai-can-help-improve-the-audit-process.html\#sthash.7ylSPw9m.dpbs. Retrieved: 3.3.2019.

Zhang, Chanyuan., Dai, Jun., Vasarhelyi, Miklos A. (2018). The Impact of Disruptive Technologies on Accounting and Auditing Education. CPA Journal, 88(9), 20-26.

(c) (1) () ()

(C) 2020 by the authors. Licensee ACRN Publishing, Austria, Editor in Chief Prof. Dr. Othmar M. Lehner. This article is an open access article distributed under the terms and conditions of the Creative Commons Attribution (CC BY SA) license (https://creativecommons.org/licenses/by-sa/4.0/) 